Gut and Liver, Vol. 11, No. 4, July 2017, pp. 535-542

\title{
Establishment of a Disease-Specific Graded Prognostic Assessment for Hepatocellular Carcinoma Patients with Spinal Metastasis
}

\author{
Chai Hong Rim ${ }^{1}$, Chiwhan $\mathrm{Choi}^{2}$, Jinhyun $\mathrm{Choi}^{3}$, and Jinsil Seong ${ }^{1}$ \\ ${ }^{1}$ Department of Radiation Oncology, Yonsei Cancer Center, Yonsei University College of Medicine, Seoul, ${ }^{2}$ Department of Radiation Oncology, \\ St. Carollo General Hospital, Suncheon, and ${ }^{3}$ Department of Radiation Oncology, Gangnam Severance Hospital, Yonsei University College of \\ Medicine, Seoul, Korea
}

\begin{abstract}
Background/Aims: Hepatocellular carcinoma (HCC) patients with spinal metastasis (SM) show heterogeneous lengths of survival. In this study, we develop and propose a graded prognostic assessment for HCC patients with SM (HCC-SM GPA). Methods: We previously reported the outcomes of $192 \mathrm{HCC}$ patients with SM who received radiotherapy from April 1992 to February 2012. Prognostic factors that significantly affected survival in that study were used to establish the HCCSM GPA. Validation was performed using an independent cohort of 63 patients recruited from September 2011 to March 2016. Results: We developed the HCC-SM GPA using the following factors: Eastern Cooperative Oncology Group performance status ( $0-2,0$ point; 3-4, 1 point), controlled primary HCC (yes, 0 point; no, 2 points), and extrahepatic metastases other than bone (no, 0 point; yes, 1 point). Patients were stratified into low ( $G P A=0$ ), intermediate ( $G P A=1$ to 2 ), and high risk (GPA=3 to 4). When applied to the validation cohort, the HCC-SM GPA determined median survival durations of 13.6, 4.8, and 2.6 months and 1-year overall survival rates of $58.3 \%, 17.8 \%$, and $7.3 \%$ for the low-, intermediate-, and highrisk patient groups, respectively $(p<0.001)$. Conclusions: Our newly proposed HCC-SM GPA successfully predicted survival outcomes. (Gut Liver 2017;11:535-542)
\end{abstract}

Key Words: Carcinoma, hepatocellular; Spinal metastasis; Graded prognostic assessment; Survival

\section{INTRODUCTION}

Although hepatocellular carcinoma (HCC) is a lethal disease, the prognosis of patients with HCC has improved continuously in recent decades, subsequent to the development of diagnostic tools and treatment modalities. ${ }^{1-3}$ Consequently, bone metastases of HCC have become a more frequent occurrence. ${ }^{1,2}$

Spinal metastasis (SM) occurs in 50\% to 75\% of cases of bone metastases of HCC and can lead to neurologic deficits and a reduced quality of life. ${ }^{4-8}$ Surgery can provide restoration of mechanical instability and emergent decompression, ${ }^{9,10}$ while chemotherapy can be used to treat systemically with targeted agent such as sorafenib. ${ }^{11-14}$ Radiotherapy (RT) can effectively provide palliation of painful SM in approximately $60 \%$ to $97 \%$ of patients, with up to $32 \%$ of patients experiencing a complete response in terms of pain relief. ${ }^{4,15,16}$ Although spinal involvement is thought to indicate a poor prognosis, ${ }^{5,16}$ patients with SM exhibit widely variable survival durations, and certain patients have favorable lifespans of up to 2 years. ${ }^{3,4,15}$ In our previous report, the follow-up times of patients ranged from 0.5 to 125 months, and 32 of 192 patients (16.7\%) survived for longer than 1 year. ${ }^{4}$ These findings suggest the necessity of accurate survival predictions that could be used to identify different prognostic groups and determine the intensity of treatment accordingly.

A graded prognostic assessment (GPA) can be defined as a prognosis-predictive scoring model derived from clinical factors found to affect survival. Following the development of a GPA for brain metastases by the Radiation Therapy Oncology Group, ${ }^{17,18}$ similar models have been developed for breast can$\mathrm{cer}^{19}$ and HCC, ${ }^{20}$ and several prognosis-predictive scoring models have been used for SM. ${ }^{21-23}$ However, an HCC-specific SM GPA has not previously been developed.

Accordingly, the present study aimed to develop a HCC-SM GPA that could be used to classify patients according to risk groups and apply treatment according to prognosis.

Correspondence to: Jinsil Seong

Department of Radiation Oncology, Yonsei Cancer Center, Yonsei University College of Medicine, 50-1 Yonsei-ro, Seodaemun-gu, Seoul 03722, Korea

Tel: +82-2-2228-8111, Fax: +82-2-2227-7823, E-mail: jsseong@yuhs.ac

Received on October 1, 2016. Revised on November 15, 2016. Accepted on December 5, 2016. Published online May 17, 2017 pISSN 1976-2283 eISSN 2005-1212 https://doi.org/10.5009/gnl16486

@ This is an Open Access article distributed under the terms of the Creative Commons Attribution Non-Commercial License (http://creativecommons.org/licenses/by-nc/4.0) which permits unrestricted non-commercial use, distribution, and reproduction in any medium, provided the original work is properly cited. 


\section{MATERIALS AND METHODS}

\section{Patient population}

In our previous study, we reported the clinical outcomes of 192 HCC patients with SM who received RT at Yonsei Cancer Center from April 1992 to February 2012. These patients were defined as the training group, and significant prognostic factors identified through a multivariate analysis were used to develop the HCC-SM GPA. To validate our HCC-SM GPA, we recruited an independent cohort of 63 patients who presented with HCC with SM at two independent hospitals with a shared university affiliation, Yonsei Cancer Center and Gangnam-Severance Hospital (45 and 18 patients, respectively) from September 2011 to March 2016

\section{Evaluation of primary tumor progression and assessment of SM}

A controlled primary tumor was defined as a lack of evidence of HCC in the liver on follow-up imaging studies conducted after treatment for HCC. ${ }^{4}$ SM was characterized by multiplicity, a mass-type nature, spinal cord compression, and pathologic fracture due to metastasis. ${ }^{4}$ A mass-type metastasis was defined as a soft tissue mass associated with bone lesion outside of the spine. Spinal cord compression was defined as radiologic tumor involvement of the spinal canal with neurologic symptoms (American Spinal Injury Association [ASIA] impairment scale of $\mathrm{A}, \mathrm{B}$, or C). ${ }^{24}$ Pathologic fracture was defined as a fracture due to a metastasis of HCC.

\section{Statistical analysis}

Overall survival was measured from the time of RT initiation. The Breslow test, which has been identified as superior for detecting early differences, ${ }^{25}$ was used to compare the survival outcomes of different risk groups. All statistical analyses were performed using SPSS version 20.0 (IBM Corp., Armonk, NY, USA). All p-values $<0.05$ were considered statistically significant.

\section{RESULTS}

\section{Patient characteristics}

In the training group, which had a median follow-up period of 4.2 months (range, 0.3 to 124.8 months) and median age of 55.5 years (range, 20 to 82 years), 181 patients (94.3\%) were followed until death. The majority of patients in this group were men (157, 81.7\%) and had a Child-Pugh class status of A (70.8\%). In addition, most patients (54.2\%) had an Eastern Cooperative Oncology Group (ECOG) performance status of $\leq 2$.

The validation group had a median follow-up period of 4.3 months (range, 0.3 to 28.8 months) and median age of 60 years (range, 38 to 82 years). In this group, 56 of 63 patients (88.9\%) were followed until death. Most of patients were men (93.7\%) and had a Child-Pugh class status of A (76.2\%) and ECOG performance score of 0-2 (88.9\%).

\section{GPA for HCC patients with SM}

In our previous study, the ECOG performance status, controlled status of primary HCC, extrahepatic metastases other than bone, and biologic equivalent dose (BED) of RT were identified as statistically significant prognostic factors affecting survival (Table 1). Because the BED is a treatment-related factor that cannot be used to predict outcomes prior to treatment, it was not included in our HCC-SM GPA. To construct the HCCSM GPA, we obtained a prognostic score for each factor using the partial score method, ${ }^{26,27}$ wherein each partial score was calculated by dividing the each magnitude of the regression coefficient by the smallest statistically significant regression coefficient and rounding each derived value to the nearest integer or the nearest integer plus 0.5. Finally, these partial scores were summed to calculate a GPA score for each patient. The parameters for which partial scores were derived were the ECOG performance status (0-2, 0 point; $3-4,1$ point), controlled status of primary HCC (controlled, 0 point; uncontrolled, 2 points), and extrahepatic metastases other than bone (no, 0 point; yes, 1 point). Scores of 0 and 4 were considered the best and worst predictive prognostic scores, respectively. Partial scores of the included factors and a definition of the HCC-SM GPA are shown in Table 2. After calculating the HCC-SM GPA by summing the partial scores of each factor, we divided the scores to form three risk groups: score of 0, low-risk group; scores of 1 to 2, intermediate-risk group; and scores of 3 to 4, high-risk group. In the training group, overall survival times among all risk groups were significantly different $(p<0.001)$, between low- and intermediate-groups ( $\mathrm{p}=0.001)$, and between intermediate- and high-risk groups ( $\mathrm{p}=0.002$ ). The median survival periods were 5.9 (95\% confidence interval [CI], 4.9 to $6.8 ; n=101), 3.4$ (95\% CI, 2.2 to $4.6 ; n=81)$, and $1.0(95 \% \mathrm{CI}, 0.7-1.3 ; n=10)$ months for the low-, intermediate-, and high-risk groups, respectively, with corresponding 6-month survival rates of 49.0\%, 24.8\%, and 10.0\%, respectively (Fig. 1).

\section{Validation}

We applied the HCC-SM GPA to our validation cohort, and observed significant differences in survival times among the risk groups (Fig. 2). The survival outcomes differed significantly among all subgroups $(\mathrm{p}<0.001)$, as well as between the lowand intermediate-risk groups $(\mathrm{p}=0.014)$ and the intermediateand high-risk groups $(\mathrm{p}<0.009)$. The median survival durations were 13.6 (95\% CI, 2.0 to $25.2 ; n=12$ ), 4.8 (95\% CI, 1.9 to 7.6 ; $\mathrm{n}=19$ ), and 2.6 (95\% CI, 1.5 to $3.7 ; \mathrm{n}=32$ ) months for the low-, intermediate-, and high-risk groups, respectively, with corresponding 6-month survival rates of $91.7 \%, 47.4 \%$, and $21.8 \%$, respectively. The summarized results are shown in Table 3.

As compared to training group, the validation group has 
Table 1. Prognostic Factor Analyses for Overall Survival of the Training Group

\begin{tabular}{|c|c|c|c|c|c|c|c|}
\hline & \multicolumn{3}{|c|}{ Univariate analysis } & \multicolumn{4}{|c|}{ Multivariate analysis } \\
\hline & No. of patients & MS, mo & p-value* & Coefficient & HR & $95 \% \mathrm{CI}$ & p-value ${ }^{\dagger}$ \\
\hline Age, yr & & & 0.492 & - & - & - & - \\
\hline$\leq 55$ & 86 & 4.8 & & & & & \\
\hline$>55$ & 106 & 3.9 & & & & & \\
\hline Gender & & & 0.430 & - & - & - & - \\
\hline Male & 157 & 4.5 & & & & & \\
\hline Female & 35 & 5.3 & & & & & \\
\hline ECOG performance status & & & $<0.001$ & 0.639 & 1.895 & $1.302-2.757$ & 0.001 \\
\hline $0-2$ & 104 & 5.7 & & & & & \\
\hline $3-4$ & 88 & 2.7 & & & & & \\
\hline AFP, ng/mL & & & 0.143 & - & - & - & - \\
\hline$\leq 200$ & 98 & 4.7 & & & & & \\
\hline$>200$ & 94 & 2.8 & & & & & \\
\hline Child-Pugh classification & & & 0.025 & 0.259 & 1.165 & $0.693-1.755$ & 0.164 \\
\hline $\mathrm{A}, \mathrm{B}$ & 172 & 4.5 & & & & & \\
\hline $\mathrm{C}$ & 20 & 2.0 & & & & & \\
\hline Primary HCC & & & $<0.001$ & 1.279 & 3.595 & $2.453-5.268$ & $<0.001$ \\
\hline Controlled & 127 & 6.2 & & & & & \\
\hline Uncontrolled & 65 & 1.9 & & & & & \\
\hline $\begin{array}{l}\text { Interval from diagnosis of primary tumor to } \\
\text { spinal metastases, mo }\end{array}$ & & & 0.966 & - & - & - & - \\
\hline$\leq 9$ & 100 & 4.2 & & & & & \\
\hline$>9$ & 92 & 4.0 & & & & & \\
\hline Baseline BPI score (pain severity) & & & 0.857 & - & - & - & - \\
\hline$\leq 6$ & 114 & 4.8 & & & & & \\
\hline$>6$ & 78 & 4.2 & & & & & \\
\hline Extrahepatic metastases other than bone & & & 0.012 & -0.560 & 0.571 & $0.391-0.835$ & 0.004 \\
\hline Yes & 50 & 2.8 & & & & & \\
\hline No & 142 & 5.0 & & & & & \\
\hline Site of spinal metastasis & & & 0.169 & - & - & - & - \\
\hline Cervical & 26 & 2.5 & & & & & \\
\hline Thoracic & 46 & 4.8 & & & & & \\
\hline Lumbar & 48 & 5.7 & & & & & \\
\hline Sacrum & 8 & 4.5 & & & & & \\
\hline Combined ( 2 sites or more) & 64 & 3.7 & & & & & \\
\hline Multiplicity of spinal metastases & & & 0.112 & - & - & - & - \\
\hline Yes & 105 & 5.0 & & & & & \\
\hline No & 87 & 3.9 & & & & & \\
\hline Mass-type metastases & & & 0.577 & - & - & - & - \\
\hline Yes & 46 & 4.7 & & & & & \\
\hline No & 146 & 4.5 & & & & & \\
\hline Spinal cord compression (ASIA scale A-C) & & & 0.839 & - & - & - & - \\
\hline Yes $(\mathrm{A}-\mathrm{C})$ & 25 & 4.0 & & & & & \\
\hline No $(D, E)$ & 167 & 4.5 & & & & & \\
\hline Pathologic fracture & & & 0.003 & -0.342 & 0.710 & $0.476-1.059$ & 0.093 \\
\hline Yes & 47 & 2.7 & & & & & \\
\hline No & 145 & 5.0 & & & & & \\
\hline $\mathrm{BED}, \mathrm{Gy}_{10}$ & & & $<0.001$ & -0.624 & 0.536 & $0.383-0.751$ & $<0.001$ \\
\hline$\leq 38$ & 38 & 2.4 & & & & & \\
\hline $39-53$ & 132 & 9.7 & & & & & \\
\hline$>53$ & 22 & 15.2 & & & & & \\
\hline Treatment modalities & & & 0.926 & - & - & - & - \\
\hline RT alone & 140 & 3.9 & & & & & \\
\hline $\mathrm{RT}+\mathrm{CTx}$ & 38 & 4.0 & & & & & \\
\hline $\mathrm{RT}+\mathrm{S}_{ \pm} \mathrm{CTx}$ & 14 & 5.3 & & & & & \\
\hline RT technique & & & 0.110 & - & - & - & - \\
\hline Conventional (2D) & 107 & 3.9 & & & & & \\
\hline 3D-CRT of IMRT & 85 & 4.5 & & & & & \\
\hline Pain response & & & 0.001 & 0.308 & 1.361 & $0.938-1.973$ & 0.104 \\
\hline CR & 41 & 7.2 & & & & & \\
\hline Non-CR & 151 & 3.0 & & & & & \\
\hline
\end{tabular}

Adapted from Choi C, Seong J. Gut Liver 2015;9:94-102. ${ }^{4}$

MS, median survival; HR, hazard ratio; CI, confidence interval; ECOG, Eastern Cooperative Oncology Group; AFP, $\alpha$-fetoprotein; HCC, hepatocellular carcinoma; BPI, brief pain inventory; ASIA, American Spinal Injury Association; BED, biologically effective dose; RT, radiotherapy; CTx, chemotherapy; S, surgery; 2D, 2-dimensional; 3D-CRT, 3-dimensional conformal radiation therapy; IMRT, intensity-modulated radiation therapy; $\mathrm{CR}$, complete pain response.

*Determined using the log-rank test; ${ }^{\dagger}$ Determined using the Cox proportional hazard model. 
Table 2. Definition of HCC-SM GPA

\begin{tabular}{lcccc}
\hline & & & & GPA \\
\cline { 3 - 5 } & Magnitude of coefficient & Partial score & 0 & 1 \\
\hline ECOG performance & 0.639 & 1 & $0-2$ & $3-4$ \\
Primary controlled & 1.279 & 2 & Controlled & Uncontrolled \\
Extrahepatic metastases other than bone & 0.571 & 1 & No & Yes \\
\hline
\end{tabular}

HCC, hepatocellular carcinoma; SM, spinal metastasis; GPA, graded prognostic assessment; ECOG, Eastern Cooperative Oncology Group performance status.

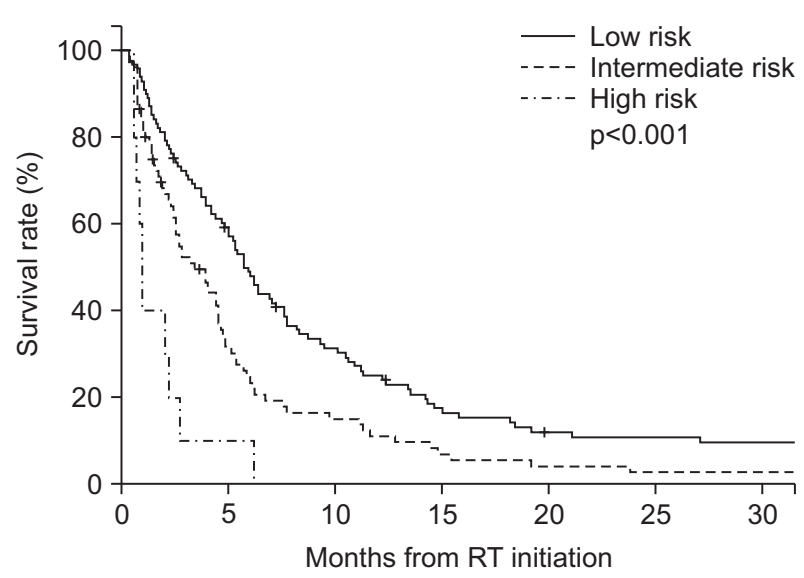

Fig. 1. Survival outcomes in the training group according to the graded prognostic assessment for hepatocellular carcinoma patients with spinal metastasis (HCC-SM GPA). The risk groups were defined as follows: low risk group, GPA score 0; intermediate risk group, GPA scores 1 to 2 ; and high risk group, GPA scores 3 to 4 . Overall survival differed among all subgroups $(\mathrm{p}<0.001)$, between the low-risk and intermediate-risk groups $(\mathrm{p}=0.001)$, and between the intermediaterisk and high-risk groups $(\mathrm{p}=0.002)$.

RT, radiotherapy.

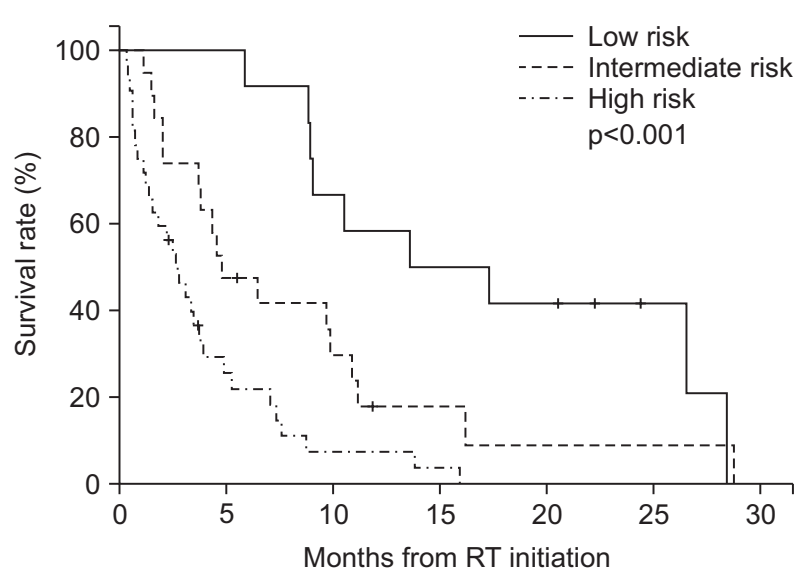

Fig. 2. Survival outcomes in the validation group according to the graded prognostic assessment for hepatocellular carcinoma patients with spinal metastasis (HCC-SM GPA). The risk groups were defined as follows: low-risk group, GPA score 0; intermediate-risk group, GPA scores 1 to 2; and high-risk group, GPA scores 3 to 4 . Overall survival differed among all subgroups $(\mathrm{p}<0.001)$, between the lowrisk and intermediate-risk groups $(\mathrm{p}=0.014)$, and between the intermediate-risk and high-risk groups ( $\mathrm{p}=0.009)$.

$\mathrm{RT}$, radiotherapy.

Table 3. Survival Results in the Validation Group According to the GPA Score

\begin{tabular}{lccccccc}
\hline & GPA score & No. & MS & 95\% CI & 1 yr 0S, \% & 6 mo 0S, \% \\
\hline Low risk & 0 & 12 & 13.6 & $2.0-25.2$ & 58.3 & 91.7 \\
Intermediate risk & $1-2$ & 19 & 4.8 & $1.9-7.6$ & 17.8 & 47.4 \\
High risk & $3-4$ & 32 & 2.6 & $1.5-3.7$ & 7.3 & 21.8 \\
\hline
\end{tabular}

GPA, graded prognostic assessment; MS, median survival; CI, confidence interval; OS, overall survival.

more patients with uncontrolled primary HCC (65.1\% vs $15.6 \%$, $\mathrm{p}<0.001)$ and extrahepatic metastases other than bone $(61.9 \%$ vs $26.0 \%, p<0.001)$. There was no statistically significant difference in patient distribution according to ECOG performance status ( $p=0.377)$. The result of survival analysis of the validation group is presented in Table 4.

\section{DISCUSSION}

In the present study, we analyzed a total of 255 HCC patients with SM, including 192 patients who were used to develop the HCC-SM GPA and 63 patients recruited for validation. We found that the risk groups stratified according to our HCC-SM GPA exhibited significant differences in survival outcomes.

Several previous studies have reported various prognostic factors that affect the survival of HCC patients with SM. Chang et $a .^{15}$ conducted one of the largest studies, evaluating 102 HCC patients with SM. The median survival interval from SM to death was 3 months, and a good performance status and response to RT were found to significantly affect survival. Goodwin et al. ${ }^{3}$ performed a meta-analysis of 26 studies that described operative techniques used to treat SM. The authors reported that patients who underwent surgery plus adjuvant therapy, including chemotherapy or RT, displayed a trend toward 
Table 4. Prognostic Factor Analysis for Overall Survival of the Validation Group

\begin{tabular}{|c|c|c|c|c|c|c|c|}
\hline & \multicolumn{3}{|c|}{ Univariate analysis } & \multicolumn{4}{|c|}{ Multivariate analysis } \\
\hline & No. of patients & MS, mo & p-value* & Coefficient & $\mathrm{HR}$ & $95 \% \mathrm{CI}$ & p-value ${ }^{\dagger}$ \\
\hline Age, yr & & & 0.058 & - & - & - & - \\
\hline$\leq 55$ & 20 & 3.4 & & & & & \\
\hline$>55$ & 43 & 5.8 & & & & & \\
\hline Gender & & & 0.567 & - & - & - & - \\
\hline Male & 59 & 4.8 & & & & & \\
\hline Female & 4 & 2.0 & & & & & \\
\hline ECOG performance status & & & $<0.001$ & 2.584 & 13.244 & $4.606-38.079$ & $<0.001$ \\
\hline $0-2$ & 56 & 5.8 & & & & & \\
\hline $3-4$ & 7 & 1.4 & & & & & \\
\hline AFP, ng/mL & & & $<0.001$ & 1.284 & 3.613 & $1.873-6.967$ & $<0.001$ \\
\hline$\leq 200$ & 32 & 9.8 & & & & & \\
\hline$>200$ & 31 & 3.0 & & & & & \\
\hline Child-Pugh classification & & & $<0.001$ & 2.868 & 17.610 & $5.262-58.933$ & $<0.001$ \\
\hline $\mathrm{A}, \mathrm{B}$ & 58 & 4.8 & & & & & \\
\hline $\mathrm{C}$ & 5 & 0.4 & & & & & \\
\hline Primary HCC & & & 0.004 & 1.054 & 2.869 & $1.425-5.778$ & 0.003 \\
\hline Controlled & 22 & 9.0 & & & & & \\
\hline Uncontrolled & 41 & 3.4 & & & & & \\
\hline $\begin{array}{l}\text { Interval from diagnosis of primary tumor to } \\
\text { spinal metastases, mo }\end{array}$ & & & 0.692 & - & - & - & - \\
\hline$\leq 12$ & 28 & 3.7 & & & & & \\
\hline$>12$ & 35 & 5.8 & & & & & \\
\hline Baseline BPI score (pain severity) & & & 0.887 & - & - & - & - \\
\hline$\leq 6$ & 40 & 4.8 & & & & & \\
\hline$>6$ & 20 & 4.5 & & & & & \\
\hline Extrahepatic metastases other than bone & & & $<0.001$ & 1.213 & 3.362 & $1.676-6.743$ & 0.001 \\
\hline Yes & 39 & 2.7 & & & & & \\
\hline No & 24 & 9.8 & & & & & \\
\hline Site of spinal metastasis & & & 0.051 & - & - & - & - \\
\hline Cervical & 2 & 10.5 & & & & & \\
\hline Thoracic & 13 & 6.4 & & & & & \\
\hline Lumbar & 6 & 7.3 & & & & & \\
\hline Sacrum & 4 & 13.8 & & & & & \\
\hline Combined ( 2 sites or more) & 38 & 3.7 & & & & & \\
\hline Multiplicity of spinal metastases & & & 0.013 & 0.635 & 1.887 & $0.976-3.648$ & 0.059 \\
\hline Yes & 41 & 3.7 & & & & & \\
\hline No & 22 & 8.9 & & & & & \\
\hline Mass-type metastases & & & 0.200 & - & - & - & - \\
\hline Yes & 29 & 3.7 & & & & & \\
\hline No & 34 & 5.8 & & & & & \\
\hline Spinal cord compression (ASIA scale A-C) & & & 0.025 & -0.072 & 0.930 & $0.424-2.040$ & 0.857 \\
\hline Yes $(\mathrm{A}-\mathrm{C})$ & 17 & 3.4 & & & & & \\
\hline No $(D, E)$ & 46 & 5.8 & & & & & \\
\hline Pathologic fracture & & & 0.301 & - & - & - & - \\
\hline Yes & 22 & 3.4 & & & & & \\
\hline No & 41 & 5.2 & & & & & \\
\hline $\mathrm{BED}, \mathrm{Gy}_{10}$ & & & 0.010 & -0.038 & 0.963 & $0.398-2.329$ & 0.932 \\
\hline$\leq 38$ & 29 & 3.0 & & & & & \\
\hline $39-53$ & 23 & 7.6 & & & & & \\
\hline$>53$ & 11 & 8.9 & & & & & \\
\hline Treatment modalities & & & 0.228 & - & - & - & - \\
\hline RT alone & 24 & 5.8 & & & & & \\
\hline $\mathrm{RT}+\mathrm{CTx}$ & 27 & 3.7 & & & & & \\
\hline $\mathrm{RT}+\mathrm{S}_{ \pm} \mathrm{CTx}$ & 12 & 8.9 & & & & & \\
\hline RT technique & & & 0.913 & - & - & - & - \\
\hline 3D-CRT or conventional 2D & 39 & 4.5 & & & & & \\
\hline IMRT or tomotherapy & 24 & 4.8 & & & & & \\
\hline Pain response & & & 0.209 & - & - & - & - \\
\hline $\mathrm{CR}$ & 13 & 8.8 & & & & & \\
\hline Non-CR & 47 & 4.3 & & & & & \\
\hline
\end{tabular}

MS, median survival; HR, hazard ratio; CI, confidence interval; ECOG, Eastern Cooperative Oncology Group; AFP, $\alpha$-fetoprotein; HCC, hepatocellular carcinoma; BPI, brief pain inventory; ASIA, American Spinal Injury Association; BED, biologically effective dose; RT, radiotherapy; CTx, chemotherapy; S, surgery; 3D-CRT, 3-dimensional conformal radiation therapy; 2D, 2-dimensional; IMRT, intensity-modulated radiation therapy; $\mathrm{CR}$, complete pain response.

*Determined using the log-rank test; ${ }^{\dagger}$ Determined using the Cox proportional hazard model. 
Table 5. Reported Series of Clinical Outcomes of Hepatocellular Carcinoma Patients with Spinal Metastasis

\begin{tabular}{|c|c|c|c|c|c|c|}
\hline Author & Study type & No. & Treatment (\%) & $\begin{array}{c}\text { OS after SM, } \\
\text { mo }\end{array}$ & $\begin{array}{l}\text { OS after treatment } \\
\text { for SM }\end{array}$ & Prognostic factor \\
\hline Chang et al. ${ }^{15}$ & Retrospective & 102 & RT (82.3), OP (8.8) & 3 & - & RT response, ECOG performance \\
\hline \multirow[t]{2}{*}{ Chang et al. ${ }^{16}$} & Retrospective & 27 (SRS group) & SRS (100), OP (10.3) & 14 & 7 & Age, Child-Pugh class, KPS \\
\hline & & 32 (cRT croup) & cRT (100) & & 3 & \\
\hline Lee et $a .^{14}$ & Retrospective & 33 & OP (100), RT (36.4) & 8.7 & 6 & Tomita score \\
\hline \multirow[t]{2}{*}{ Sohn et $a{ }^{28}$} & Retrospective & 28 (SRS group) & SRS (100), OP (10.3) & - & 8 & - \\
\hline & & 28 (cRT group) & cRT (100), OP (10.3) & & 10 & \\
\hline Goodwin et $a l^{3}$ & Meta-analysis & $\begin{array}{l}26 \text { Articles, } \\
152 \text { patients }\end{array}$ & OP (84.2), RT (61.8) & 10.6 & - & Multimodal treatment \\
\hline
\end{tabular}

OS, overall survival; SM, spine metastasis; RT, radiotherapy; OP, operation; ECOG, Eastern Cooperative Oncology Group performance status; SRS, stereotactic radiosurgery; KPS, Karnofsky Performance Status scale; cRT, conventional RT.

longer survival when compared to patients treated with either modality alone or subjected to observation. The other clinical prognostic factors were not reported due to low or insufficient statistical strength, because most of the recruited studies were case series. Other studies reported age, Child-Pugh class, Karnofsky performance status scale, and Tomita score (Table 5) as significant factors affecting survival. ${ }^{14,16,28}$ However, reports of these prognostic factors were heterogeneous, and the number of studies and number of patients included in each study were relatively small. Therefore, the available information about these previously identified prognostic factors was not sufficient to make treatment decisions.

Previously, other authors attempted to stratify the risks of patients with SM and suggested treatment strategies. For example, the Tomita and Tokuhashi scoring systems, which were developed by orthopedic surgeons, are popular models used to predict the prognosis of patients with SM from various cancers. $^{21,22}$ The Tomita system includes prognostic parameters of the primary tumor site, visceral metastases, and multiplicity of bone metastasis, whereas the Tokuhashi system incorporates the performance status, number of non-spinal bone metastases, major organ metastasis, primary tumor site, and degree of palsy. ${ }^{29}$ However, these systems are not easily applied to HCC patients with SM, as survival of HCC patients is largely affected by the primary cancer control status. Furthermore, those systems recommend treatment strategies that mainly focus on spinal surgery, rather than other modalities such as RT or primary cancer treatment.

As noted above, the GPA was originally developed as a prognostic index and quantitative evaluation tool to help clinicians make treatment decisions regarding patients with brain metastases. The GPA has been widely implemented because of its comprehensive nature, ease of use, and good ability to predict prognosis. $^{17,18}$ Since the original GPA was developed for brain metastases regardless of any primary cancer, is also not easily applied to HCC. Thus disease specific HCC-GPA was developed and has been clinically useful. ${ }^{20}$ A similar HCC-specific GPA is needed for patients with SM. Our HCC-SM GPA incorporated three important and well-known prognostic factors: ECOG performance status, primary HCC control status, and extrahepatic metastases other than bone. Furthermore, the HCC-SM GPA was based on a relatively large number of patients and was designed for simplicity and ease of use.

Use of the HCC-SM GPA for patient stratification will allow physicians to apply tailored treatment options according to an individual patient's life expectancy. The low-risk group, characterized by a favorable performance status and limited extent of non-spinal disease, had a median survival of 13.6 months and 1-year survival rate of 58.3\%. This group might accordingly be offered an active therapeutic approach that includes local treatments such as surgery or stereotactic body radiotherapy, ${ }^{14,30-32}$ which could ameliorate pain or neurologic symptoms and consequently enhance quality of life, and might even yield a nearcure of oligometastases. ${ }^{33-36}$ The intermediate-risk group, which had a median survival of 4.8 months and a 6-month survival rate of 47.4\%, encompasses various clinical conditions, and patients in this group should be treated on an individual basis with consideration of their performance status and extent of metastases. The high-risk group, characterized by uncontrolled primary HCC with a poor performance status or a nonspinal metastatic burden, had a median survival duration of only 2.6 months and a 6-month survival rate of $21.8 \%$. For this group, supportive and hospice care would be the best option, thus allowing patients to avoid unnecessary physical or economic burdens from medical treatment.

Beyond treatment strategy decisions, our HCC-SM GPA could also be applied to clinical trial design; for example, researchers could categorize patients according to predicted survival and therefore balance the assortment of patients into individual groups. Furthermore, this tool would be useful for comparing the results of different studies.

Our study had several limitations. First, the number of patients in the validation cohort was relatively small, and approximately half of the patients were classified as being at high risk, 
whereas only 12 were classified as being at low risk. Therefore, further verification may be needed. Second, our study included only patients who received RT of the spine. The exclusion of patients whose conditions were deemed insufficient for RT or who did not receive RT because of personal or physicians' preferences might have introduced bias.

In conclusion, the HCC-SM GPA might facilitate the selection of patients who are candidates for active local treatment, and could identify high-risk patients who would benefit from best supportive care. To the best of our knowledge, the HCC-SM GPA, which includes prognostic factors identified in a relatively large, disease-specific study, is the first HCC-specific prognostic model for SM. Further validation and utilization in various patient groups are warranted to establish its efficacy.

\section{CONFLICTS OF INTEREST}

No potential conflict of interest relevant to this article was reported.

\section{ACKNOWLEDGEMENTS}

This study was supported by a grant of the Korean Health Technology R\&D Project (A121982), Ministry of Health \& Welfare, Republic of Korea.

\section{REFERENCES}

1. Fukutomi M, Yokota M, Chuman $\mathrm{H}$, et al. Increased incidence of bone metastases in hepatocellular carcinoma. Eur J Gastroenterol Hepatol 2001;13:1083-1088.

2. Santini D, Pantano F, Riccardi F, et al. Natural history of malignant bone disease in hepatocellular carcinoma: final results of a multicenter bone metastasis survey. PLoS One 2014;9:e105268.

3. Goodwin CR, Yanamadala V, Ruiz-Valls A, et al. A systematic review of metastatic hepatocellular carcinoma to the spine. World Neurosurg 2016;91:510-517.e4.

4. Choi C, Seong J. Predictive factors of palliative radiotherapy response and survival in patients with spinal metastases from hepatocellular carcinoma. Gut Liver 2015;9:94-102.

5. He J, Zeng ZC, Fan J, et al. Clinical features and prognostic factors in patients with bone metastases from hepatocellular carcinoma after liver transplantation. BMC Cancer 2011;11:492.

6. Kim SU, Kim DY, Park JY, et al. Hepatocellular carcinoma presenting with bone metastasis: clinical characteristics and prognostic factors. J Cancer Res Clin Oncol 2008;134:1377-1384.

7. Kaizu T, Karasawa K, Tanaka Y, et al. Radiotherapy for osseous metastases from hepatocellular carcinoma: a retrospective study of 57 patients. Am J Gastroenterol 1998;93:2167-2171.

8. Seong J, Koom WS, Park HC. Radiotherapy for painful bone metastases from hepatocellular carcinoma. Liver Int 2005;25:261265.
9. Joaquim AF, Powers A, Laufer I, Bilsky MH. An update in the management of spinal metastases. Arq Neuropsiquiatr 2015;73:795-802.

10. Klimo P Jr, Schmidt MH. Surgical management of spinal metastases. Oncologist 2004;9:188-196.

11. Kim JW, Lee JO, Han SW, et al. Clinical outcomes of sorafenib treatment in patients with metastatic hepatocellular carcinoma who had been previously treated with fluoropyrimidine plus platinum-based chemotherapy. Am J Clin Oncol 2011;34:125-129.

12. Nakano M, Tanaka M, Kuromatsu R, et al. Sorafenib for the treatment of advanced hepatocellular carcinoma with extrahepatic metastasis: a prospective multicenter cohort study. Cancer Med 2015;4:1836-1843.

13. DU J, Qian X, Liu B. Long-term progression-free survival in a case of hepatocellular carcinoma with vertebral metastasis treated with a reduced dose of sorafenib: case report and review of the literature. Oncol Lett 2013;5:381-385.

14. Lee MH, Lee SH, Kim ES, Eoh W, Chung SS, Lee CS. Survivalrelated factors of spinal metastasis with hepatocellular carcinoma in current surgical treatment modalities: a single institute experience. J Korean Neurosurg Soc 2015;58:448-453.

15. Chang SS, Luo JC, Chao Y, et al. The clinical features and prognostic factors of hepatocellular carcinoma patients with spinal metastasis. Eur J Gastroenterol Hepatol 2001;13:1341-1345.

16. Chang UK, Kim MS, Han CJ, Lee DH. Clinical result of stereotactic radiosurgery for spinal metastasis from hepatocellular carcinoma: comparison with conventional radiation therapy. J Neurooncol 2014;119:141-148.

17. Sperduto CM, Watanabe Y, Mullan J, et al. A validation study of a new prognostic index for patients with brain metastases: the graded prognostic assessment. J Neurosurg 2008;109 Suppl:87-89.

18. Sperduto PW, Berkey B, Gaspar LE, Mehta M, Curran W. A new prognostic index and comparison to three other indices for patients with brain metastases: an analysis of 1,960 patients in the RTOG database. Int J Radiat Oncol Biol Phys 2008;70:510-514.

19. Sperduto PW, Kased N, Roberge D, et al. Effect of tumor subtype on survival and the graded prognostic assessment for patients with breast cancer and brain metastases. Int J Radiat Oncol Biol Phys 2012;82:2111-2117.

20. Lim S, Lee S, Lim JY, et al. Hepatocellular carcinoma specific graded prognostic assessment can predict outcomes for patients with brain metastases from hepatocellular carcinoma. J Neurooncol 2014;120:199-207.

21. Tokuhashi Y, Matsuzaki H, Oda H, Oshima M, Ryu J. A revised scoring system for preoperative evaluation of metastatic spine tumor prognosis. Spine (Phila Pa 1976) 2005;30:2186-2191.

22. Tomita K, Kawahara N, Kobayashi T, Yoshida A, Murakami H, Akamaru T. Surgical strategy for spinal metastases. Spine (Phila Pa 1976) 2001;26:298-306.

23. Fourney DR, Frangou EM, Ryken TC, et al. Spinal instability neoplastic score: an analysis of reliability and validity from the spine oncology study group. J Clin Oncol 2011;29:3072-3077. 
24. Ditunno JF Jr, Young W, Donovan WH, Creasey G. The international standards booklet for neurological and functional classification of spinal cord injury: American Spinal Injury Association. Paraplegia 1994;32:70-80.

25. Kleinbaum DG. Survival analysis: a self-learning text. New York: Springer-Verlag, 1996.

26. Chow E, Abdolell M, Panzarella T, et al. Predictive model for survival in patients with advanced cancer. J Clin Oncol 2008;26:58635869.

27. Chow E, Ding K, Parulekar WR, et al. Predictive model for survival in patients having repeat radiation treatment for painful bone metastases. Radiother Oncol 2016;118:547-551.

28. Sohn S, Chung CK, Sohn MJ, Kim SH, Kim J, Park E. Radiosurgery compared with external radiation therapy as a primary treatment in spine metastasis from hepatocellular carcinoma: a multicenter, matched-pair study. J Korean Neurosurg Soc 2016;59:37-43.

29. Aoude A, Amiot LP. A comparison of the modified Tokuhashi and Tomita scores in determining prognosis for patients afflicted with spinal metastasis. Can J Surg 2014;57:188-193.

30. Kim CH, Chung CK, Jahng TA, Kim HJ. Surgical outcome of spinal hepatocellular carcinoma metastases. Neurosurgery 2011;68:888896.

31. Lee E, Kim TG, Park HC, et al. Clinical outcomes of stereotactic body radiotherapy for spinal metastases from hepatocellular carcinoma. Radiat Oncol J 2015;33:217-225.

32. Wang XS, Rhines LD, Shiu AS, et al. Stereotactic body radiation therapy for management of spinal metastases in patients without spinal cord compression: a phase 1-2 trial. Lancet Oncol 2012;13:395-402.

33. Niibe Y, Hayakawa K. Oligometastases and oligo-recurrence: the new era of cancer therapy. Jpn J Clin Oncol 2010;40:107-111.

34. Hellman S, Weichselbaum RR. Oligometastases. J Clin Oncol 1995;13:8-10.

35. Ahmed KA, Torres-Roca JF. Stereotactic body radiotherapy in the management of oligometastatic disease. Cancer Control 2016;23:21-29.

36. Dagan R, Lo SS, Redmond KJ, et al. A multi-national report on stereotactic body radiotherapy for oligometastases: patient selection and follow-up. Acta Oncol 2016;55:633-637. 